\title{
Artur Corvelo: mais uma vítima de Eça de Queirós
}

\author{
Bruna Maria Severino Bicudo
}

\begin{abstract}
Resumo: Este trabalho tem como objetivo promover a análise do personagem Artur Corvelo, protagonista de A Capital - uma obra escrita por Eça de Queirós, ainda pouco (re)conhecida e estudada nos ambientes acadêmicos. No intuito de valorizar a produção queirosiana como um todo e contribuir para o aumento do referencial teórico sobre os personagens masculinos influenciados pela literatura ultrarromântica, as bases bibliográficas e demais referências foram alicerçadas em autores de crítica literária e demais estudiosos da literatura. Por meio da realização deste material, pode-se considerar Artur Corvelo como um ser metonímico de Portugal, alvo da crítica mordaz e impetuosa de seu criador, cujo olhar crítico sobre a decadência da pátria lusitana só lhe permitiu criar seres fadados à ruína. Ademais, o personagem dessa análise e a obra na qual está inserido levam-nos a refletir sobre as relações estabelecidas entre leitores e leitura.

Palavras-chave: Artur Corvelo; A Capital; Eça de Queirós.

Abstract. This paper analyzes the main character Artur Corvelo in the book A Capital (which is still not very recognized or studied in academic circles) written by Eça de Queirós. The purpose is to value the production of Queirós and his contribution to the increase in the number of theoretical material about the male characters influenced by the super-romantic literature. The research provided and understanding of Artur as a metonymic of Portugal, which was the target of cutting remarks and impetuous criticism of his author. Eça's criticism about the Portuguese decadence allowed him to create characters doom to failure. The character of this analysis and the work in which he appears, leads to a reflection about the relationship between readers and readings.
\end{abstract}

Keywords. Artur Corvelo; A capital; Eça de Queirós.

Introdução

Pode-se escrever e pintar qualquer coisa, pois sempre haverá alguém para compreendê-la (para achar-lhe sentido).

Pablo Picasso

Eça de Queirós é, possivelmente, o maior representante de um movimento literário do século XIX, o qual "adota o mundo real como pano de fundo" (ECO, 1994, p.89). Esse autor retratou os males da pátria portuguesa, em uma linguagem tão trabalhada e próxima de seus leitores que fez muitos de seus compatriotas esquecerem a ironia e a crueldade presentes na grande maioria de suas obras.

"Bruna Maria Severino Bicudo, graduada em Letras Português/Inglês. Universidade Estadual de Ponta Grossa - UEPG - E-mai: bruna_maria21@hotmail.com 
Além disso, Eça caricaturou a elite oficial (jornalistas, aristocratas, servidores públicos) e criticou a hipocrisia e o provincianismo da sociedade por meio de uma literatura ácida e revolucionária, na qual defendia a necessidade de a arte reproduzir os desvios da burguesia, a falta de tradição filosófica e científica do próprio país e os males morais pertencentes ao clero.

$\mathrm{O}$ autor de $O$ primo Basílio aproximou a literatura do mundo real e demonstrou grande preocupação frente às consequências de uma educação romanesca e seus resultados na fase adulta dos personagens, utilizados como um retrato da realidade. Grande parte das obras de Eça atesta que, no século XIX, homens e mulheres eram vítimas de uma educação deficiente, a qual não permitia uma abordagem correta (distinção entre ficção e realidade) dos textos de Walter Scott, Alexandre Dumas, Vitor Hugo, Almeida Garrett, Byron, entre outros que exploravam o ultrarromantismo e as aventuras medievais. Tais obras, segundo o próprio Eça de Queirós, apoiadas pelo sistema educativo falho, promotor de leituras acéfalas, não contribuíam para o desenvolvimento da razão e acabavam auxiliando a incapacidade de seus leitores para refletirem sobre os atos cometidos não só por eles mesmos, mas também pelos demais personagens que os cercavam.

Este trabalho tem por objetivo analisar um dos romances de Eça de Queirós, mais especificamente um protagonista, cujo comportamento romântico, apoiado em mimos familiares excessivos e alimentado por uma educação vaga, acaba atuando como transformador e deformador de caracteres. O livro é $A$ Capital e o personagem desse estudo chama-se Artur Corvelo - um dos escritores (ou pseudoescritores) de maior destaque no universo da escrita queirosiana.

Artur é um personagem que funciona como "uma imagem da literatura na ficção de um escritor que muito pensou a literatura antes de a escrever e enquanto escrevia" (REIS, 1999, p.93). Essa figura, que de certa forma simboliza o ápice da crítica eciana ao sentimentalismo romântico, também protagoniza este estudo, pois representa uma metonímia de tudo aquilo que essa obra póstuma quis criticar: educação romanesca, literatura/literatos ordinários e fúteis presentes na sociedade portuguesa do século XIX. Esse personagem afirma, de acordo com as obras lidas em seu mundo, a leitura como uma peça de extrema importância na caracterização dos personagens queirosianos. Tal fato pode ser facilmente comprovado por obras como $\mathbf{O}$ primo Basílio e sua protagonista Luísa, a qual não possuía condições intelectuais para distinguir a ficcionalidade 
daquilo que lia e a realidade de sua própria vida - passa grande parte do enredo lendo romances românticos, tais como A dama das camélias - exemplar mantido oculto, como se pode verificar no seguinte trecho "[Luísa] Tornou a espreguiçar-se. E saltando na ponta do pé descalço, foi buscar ao aparador por detrás de uma compota um livro um pouco enxovalhado [...] começou a ler, toda interessada [...] Era a Dama das camélias [...]" (QUEIRÓS, 1997, p.17).

Além de Luísa, há Ernestinho Ledesma, um personagem secundário de $O$ primo Basílio, que possivelmente lera muitos romances românticos antes de redigir seu drama Honra e paixão. Há também Tomás de Alencar, o poeta medíocre de $O s$ Maias, escritor de estrofes cujos versos representam a empáfia literária presente nos discursos políticos do século XIX e Gonçalo Ramires, de $A$ ilustre casa de Ramires, o fidalgo que vê na escrita o prestígio social necessário ao ingresso na política: não possui talentos literários e sua novela histórica é apenas a versão em prosa de um poema já escrito.

Os exemplos acima citados poderiam ser de número muito maior se esta análise englobasse os demais personagens ecianos amantes da leitura e da escrita, os quais indissociam suas atitudes físicas e seus perfis morais do mundo ficcional que os rodeia. A apresentação desses perfis de modo completo seria uma tarefa abrangente demais, não direcionada aos propósitos deste estudo.

O presente trabalho situa-se da seguinte forma: no primeiro momento, há uma revisão crítica do autor Eça de Queirós e sua inscrição na literatura, não como mero escritor, mas também como criador de tipos literários. O passo seguinte é a exposição de alguns aspectos de $A$ Capital e a análise de seu protagonista Artur Corvelo, no contexto de sua obra. O último momento deste artigo é dedicado às considerações finais.

1. Eça de Queirós: um prosador bárbaro

A literatura que não respira o mesmo ar da sociedade sua contemporânea, que não espelha seus sofrimentos e seus medos, nem previne contra males morais e sociais... é mera maquilagem literária.

Alexander Soljenitsin

Nas fronteiras aqui impostas, é de extrema importância reconhecer Eça de Queirós como um autor que tornou visível a seus leitores toda a inten- 
sidade do universo que representava, tendo na maestria linguística (linguagem menos rebuscada, mais objetiva) e no painel de sua época os principais pontos de apoio.

Portugal e a sociedade responsável por sua composição foram encarados como matéria-prima artística e pano de fundo dos enredos ecianos. Tais escritos, ao considerarem os aspectos sociais, iam além da superficialidade de meras relações sociais: costumes, protótipos humanos e paisagens tornaram-se possível centro revelador de um mundo até então escondido pelo falso moralismo e por uma comunidade que talvez, não aceitasse a própria decadência, nem promovesse ações de reparo - acomodava-se nas poltronas dos teatros... E assistia à vida passar, como se as obras de ficção lidas fossem bem mais surpreendentes que a biografia real que lhes coubera.

Grande parte dos personagens de Eça está, desde o princípio das narrativas, fadada à ruína. O livre-arbítrio não faz parte de muitas das obras da ficção eciana, nas quais o homem é retratado como um ser condenado pela doutrina determinista, em voga no século XIX: Artur Corvelo, Luísa, Tomás de Alencar e Gonçalo Ramires são exemplos de tipos humanos insólitos e dependentes, cujos comportamentos eram tolerados ou até mesmo incentivados por falsas amizades e relações de interesse (parasitismo).

A maioria das obras escritas por Eça leva-nos a descrevê-las como uma exposição caligráfica, crítica e ácida dos retratos de um país do século XIX estacionado no tempo, quando as sensações novas eram sinônimas de adultérios, livros eram lidos por mero convencionalismo e o esforço literário não passava de excessiva vaidade. $\mathrm{O}$ autor português, muito possivelmente, tenha exposto ao mundo as chagas da sociedade em que vivia, descrevendo de maneira irônica e satírica os aspectos promotores de sua indignação frente à pátria.

Nos romances ecianos, é nítido um trabalho alicerçado no tripé arte, história e tempo, provavelmente realizado por meio de observações pacientes, as quais objetivavam a reprodução de tipos humanos na obra literária. O próprio autor português escrevera em 1867 ao amigo Mayer: "Na arte só tem importância os que criam almas, e não os que reproduzem costumes" (apud VIANA FILHO, 1984, p.23). Embora sabendo que um autor não possui conhecimento e distanciamento crítico capazes de torná-lo um analista da própria obra, essa citação eciana permite-nos refletir sobre a importância da criatividade literária na construção de enredos e personagens, os quais, se atrelados à realidade, 
devem somar ao reflexo do mundo exterior que os cerca a liberdade ficcional de recriação de almas pertinentes ao mundo da literatura.

A fim de pragmatizar essa afirmação, iniciamos a análise da obra cujo protagonista e seu único interesse, a literatura romântica, são utilizados como armas ecianas de ataque à crível imutabilidade da capital portuguesa.

\section{A Capital: retratos de uma decadência}

Mas a presença do livro e da leitura no romance queirosiano ultrapassa a ficcionalização da realidade cultural em que se movia a média burguesia urbana. Inscrita na ficção, a leitura passa a funcionar como objeto, participa na construção do espaço, revelando-se frequentemente um elemento indissociável da atitude física da personagem.

Maria do Rosário Cunha

Alguns estudiosos pouco comprometidos com discussões acadêmicas elevam Artur Corvelo à expressão do eu psicológico de Eça de Queirós. Muitos críticos contemporâneos, por sua vez, defendem a intransitividade da literatura, a qual ultrapassa questões individuais e circunstanciais, como já afirmava Rimbaud em 1870: "Eu é um outro" (apud PERRONE-MOISÉS, 1998, p.167). Neste trabalho, consideraremos o protagonista de $A$ Capital como um sujeito imaginário de existência real apenas nas fronteiras literárias que nos cercam (leitor + obra), pois compreender essa obra póstuma como mera descrição autobiográfica seria destituí-la de toda sua função de (re)conhecimento da sociedade lisboeta do século XIX, negando a universalidade de seus temas (educação deficiente, hipocrisia social, fraqueza de caráter etc.).

Publicado em 1925, A Capital faz parte de um dos manuscritos que José Maria, filho de Eça de Queirós, achou em uma mala velha onde estavam guardados todos os manuscritos e demais rascunhos encontrados no escritório do autor português após sua morte. Ao ser publicado, o romance sofreu modificações: José Maria suprimiu um personagem denominado Cristina, prima apaixonada por Artur, a qual via Lisboa com olhos de mulher enciumada, uma vez que a capital portuguesa levaria o amado para longe de seus braços. Coube a Helena Cidade Moura, na edição da Obra completa de Eça de Queirós (Rio de 
Janeiro: José Aguilar, 1970), o reconhecimento de tal personagem. É relevante citar uma segunda edição dessa mesma obra, organizada pela professora Beatriz Berrini, em 1997, e que também manteve Cristina. Esses escritos afirmam a necessidade de se publicar a versão autógrafa de $A$ Capital, que mesmo sem ter sido finalizada pelo próprio autor clama por autenticidade.

O livro aqui analisado, assim como outras obras ecianas ( $O$ primo Basílio, O crime do padre Amaro, Os Maias), representa uma denúncia das falsas bases da sociedade da capital portuguesa do século XIX, pois mostra a influência do ambiente na formação de caracteres humanos - "a educação incompleta, incerta e falhada; a degradação moral que havia se tornado norma e estímulo aos intuitos mais baixos; a sociedade; na decadência que tudo aceita e tudo tolera" (LINS, 1939, p.96). O texto eciano, por seus temas e tipos diversos, quiçá possa ser encarado como um documento humano e social da pátria portuguesa.

Eça de Queirós despendeu vários anos de sua vida na escrita de $A$ Capital, até pô-lo de uma vez por todas em uma gaveta. Acreditamos não ser um erro dizer que Eça repelia essa obra, ou ao menos esperava alcançar uma sólida reputação como escritor antes de publicar algo que representasse uma "violenta condenação de toda a sociedade constitucional" (QUEIROZ, 1878 apud MATOS, 1998, p.150). O escritor lusitano também destinara adjetivos como frio, artificial, mosaico laborioso e personagens empalhados para descrever a própria obra nas inúmeras correspondências que o mantinham em contato com os companheiros de escrita em Portugal, durante o tempo passado fora da pátria, no qual trabalhara como diplomata. Talvez tenha sido pelas declarações e depreciações críticas escritas aos amigos que o autor tenha adiado o término de $A$ Capital centenas de vezes.

O crítico francês Jean Girodon reconheceu com entusiasmo ser esse romance eciano "um grande e belo painel da sociedade portuguesa do fim do século XIX" (apud VIANA FILHO, 1984, p.130). Porém, em fevereiro de 1881, Eça afirmou em mais uma carta ao amigo Ramalho: "interrompi $A$ Capital, estragando-a para sempre, creio eu, porque vejo agora que não poderei recuperar o fio de veia e de sentimento que ela ia tratada" (apud VIANA FILHO, 1984, p.150). Esta citação confirma que Eça de Queirós, assim como os demais colegas de profissão dos diversos movimentos literários, não estava habilitado a emitir julgamentos de valor sobre o que escrevia.

Devido a esse adiamento, ou mesmo desistência de progressão, $A$ Capital acabou sendo publicada anos depois da morte de seu autor, sem passar 
pela revisão crítica eciana, a qual buscava o "encaixe perfeito" das palavras, não tirando proveito da "ânsia de perfeição" (QUEIROZ, 1881 apud ibid., p.36) que tanto o torturara e o levava a revisar suas obras periodicamente.

A fim de classificar a obra aqui analisada como uma das grandes obras da modernidade, apropriamo-nos das palavras de um autor que via o esboço como característica da arte moderna, Charles Baudelaire: "[...] podem chamar isso de esboço, se quiserem, mas esboço perfeito" (apud COMPAGNON, 1996, p.28, grifo nosso). Mesmo sem ter sido revisada de acordo com os padrões de seu escritor, contar com um enredo linear e não possuir uma edição claramente finalizada, A Capital talvez seja um exemplo das grandes obras, não só de Eça de Queirós, mas também da literatura moderna.

\section{Artur: um poeta em branco}

E tão sem história como rola um rio lento numa solidão.

Eça de Queirós

Já no primeiro capítulo de $A$ Capital, um retrato do protagonista Artur Corvelo nos é apresentado: logo ao nascer, na província de Ovar, é colocado em meio a perspectivas românticas e literárias, pois o nome que lhe é dado pela mãe (instrumentista) representa o encantamento desta frente "[...] aos tempos de harpa e dos cavaleiros de xácara, cujos amores e proezas na Terra Santa tanto a tinham comovido" (QUEIRÓS, s/d, p.15). Se não bastasse a influência materna, Artur possuía em sua árvore genealógica o bisavô paterno poeta $\mathrm{e}$ um pai cujo talento literário permitiu-lhe escrever duas Meditações funerárias. Além disso, este nutria a esperança de o filho cultivar as belas letras e a eloquência, obtendo por meio delas uma vida ilustre e elevada posição social.

Quando criança, Artur passava os finais de tarde lendo, alimentando-se de romances românticos, tais como as novelas da Biblioteca das damas. Superprotegido pelos mimos da mãe e pelos cuidados paternos em excesso, o rapaz desenvolveu uma mente dócil, promotora de comportamentos pueris.

\footnotetext{
${ }^{1}$ Obra escrita no século XIX, uma das numerosas coleções que logo no título revelavam o tipo de leitor ao qual eram destinadas. Maria do Rosário Cunha descreveu contemporaneamente tais escritos como exemplo de manual recreativo. Uma vez relacionado ao personagem Artur Corvelo, "configura o universo cultural marcadamente romântico que o absorve desde criança” (CUNHA, 2004, p.209-10). 
Frequentara um sistema educativo deficiente (sem recursos financeiros e humanos), o qual não cedia espaço à reflexão dos estudantes, principalmente aquelas relacionadas às obras literárias. Deste modo, o jovem de Ovar transforma-se em um idealista romântico, fadado pelo determinismo eciano a uma vida monótona, com um final muito distante daqueles pertencentes aos enredos românticos lidos durante a infância e a juventude. Mais tarde, essas histórias foram transformadas por Artur em um modo de vida a ser seguido (amou idealmente uma senhora mais velha e outra com a qual nunca conversara, apaixonou-se por uma mulher casada, manteve relações superficiais e começou a embebedar-se a fim de seguir a tradição cultuada pelas paixões poéticas presentes em seus livros de cabeceira). Essas preferências literárias refletiam-se também nos versos que escrevia e em seu perfil psicológico-moral, ou seja, os romances lidos eram utilizados na construção de uma imagem idealizada da realidade.

A fim de terminar os estudos, Artur é mandado pelo pai a Coimbra, onde inicia suas relações com tipos humanos extremamente literários, verdadeiros gênios da eloquência - pelo menos era assim que os encarava, em sua debilidade mental e caráter (de)formado por ideais confusos e indefinidos. Dentre as novas amizades, é possível destacar a figura de Damião, por esse ter sido o primeiro a reconhecer a mediocridade dos versos líricos de Artur, utilizados não só para compor caderninhos de papel (cosidos e cobertos por capas cor-de-rosa pelo próprio Artur durante a infância), mas também para conquistar cortesãs durante as noites boêmias.

Após a morte do pai, gasta todo o dinheiro que conseguira com a venda dos bens familiares no patrocínio de orgias e na compra de livros (que mais tarde vendeu, quando percebeu que o dinheiro estava acabando). Sem recursos financeiros, vê como única alternativa de sobrevivência escrever uma carta a duas tias distantes, moradoras da pequena Oliveira-de-Azeméis: Ricardina e Sabina, as quais, impressionadas com a eloquência que o sobrinho demonstrara no escrito, aceitam-no. Artur abandona Coimbra e parte para a província:

"Começou então para Artur uma vida desgraçada, em que os dias se seguiam como as páginas brancas de um livro que se vai tristemente folheando. Toda manhã, as duas senhoras faziam a sua meia na sala, com as janelas cerradas, o soalho regado, num silêncio em que errava a sussuração das moscas." (QUEIRÓS, 19--, p.30) 
Por insistência das tias, tornou-se praticante de farmácia (profissão logo abandonada, mas retomada posteriormente à desilusão completa de sua biografia). A vida tediosa levara-o a dedicar-se com afinco à literatura lírica: decide então escrever uma obra na qual pudesse reunir suas poesias e escolhe o título Esmaltes e joias. Com ela, almejava ver seu nome estampado nos folhetins, alcançando a celebridade por meio das letras, como antevia o próprio pai. Porém, Oliveira-de-Azeméis não representava para Artur o palco ideal onde faria o show de suas habilidades poéticas - afinal, uma "vilota odiosa e sufocante" (CANDIDO, 1964, p.41) pouco teria a oferecer a um escritor tão talentoso.

A única diversão de Artur na província era ler os versos que compunha a Rabecaz - um pândego que admirava os dotes do companheiro em troca de jantares gratuitos e cavaqueiras: "[...] Está de arromba! Irra! [...] Artur, comovido, pagou a ceia" (QUEIRÓS, 19--, p.51). Além de admirar os versos de Artur, Rabecaz, por já ter vivido em Lisboa, aquecia no pseudopoeta o desejo de abandonar o interior e partir para a capital em busca de reconhecimento. Essa vontade de deixar a província é inflamada por uma carta de Damião, na qual este chama o companheiro de Coimbra a Lisboa: "A capital é, no fim de tudo, $\mathrm{o}$ único ponto vivo desta fétida lesma morta que se escapa à beira do velho Atlântico, sob o nome desacreditado de Portugal [...]" (QUEIRÓS, 19--, p.46).

O protagonista de $A$ Capital, após receber herança de um padrinho que pouco conhecera, consegue sair de Oliveira-de-Azeméis, deixando para trás apenas as chorosas lamentações da tia Sabina - a única que nutria sentimentos sinceros por ele. Leva como bagagem, além do manuscrito de Esmaltes ejoias (cujos versos seriam publicados, mas nunca vendidos), sua nova aposta para obter o sucesso: o drama filosófico Amores de poeta (definido, mais tarde, como um drama cujo enredo precisaria ser reescrito a fim de ser representado).

Ao chegar à capital, muito impressionado com a nova paisagem, imagina situações, idealizando o lugar onde acabara de chegar:

"Quantos amores, quantos mistérios, crimes talvez! Ali jornalistas compunham artigos; oradores preparavam discursos; estadistas conferenciavam; mulheres aristocratas, nas suas salas, falavam de amores, e, nos pianos ricos, gemiam as cavatinas apaixonadas. Que grande Lisboa!" (QUEIROZ, s/d, p.71) 
Devidamente instalado em um hotel, Artur relê os versos que compôs em Oliveira e estes lhe parecem pueris se comparados à genialidade literária que o poeta provinciano supunha existir em Lisboa. Mesmo insatisfeito com suas produções, decide continuar na capital.

Aos poucos, Artur Corvelo conhece profissionais liberais, políticos e demais membros da aristocracia lisboeta, tais como o jornalista Melchior, que fazia uso da eloquência necessária à publicidade para bajular os integrantes do high life. Começa, a partir dessa relação, todo um ciclo de amizades parasíticas, de ostentação, de reconhecimento da capital Lisboa recriada por Eça, a qual, dia após dia, mostrava ao poeta de Oliveira-de-Azeméis suas facetas, nada relacionadas à civilização superior idealizada pelo caráter parvo e pela vaidade e ambição de atingir a glória e integrar a alta sociedade por meio da única habilidade que cultivara durante toda vida: a bazófia.

Os relacionamentos do personagem central com a sociedade de Lisboa contribuíram ainda mais para a deformação de sua personalidade, pois as pessoas só se afeiçoavam a ele depois de saberem que ele havia herdado uma boa quantia, e desse modo é explorado por aqueles que acredita lhe devotarem uma amizade sincera, uma admiração por seus escritos. Influenciado por esses contatos, o poeta eciano entrega-se ao luxo e às excentricidades permitidas pelo dinheiro, e em meio à vida luxuosa, repleta de magnificências, sentia-se "[...] com preguiça de trabalhar no seu livro, ficava-se a contemplar, numa vaga e distante fulguração, a celebridade que ele lhe traria" (QUEIRÓS, 19--, p.94).

Em troca de promessas de publicação de Esmaltes e joias e da apresentação do seu drama a grandes empresários do ramo, Artur gasta grande parte do seu dinheiro em jantares, em pândegas, em roupas utilizadas durante as soirré do high life lisboeta e é justamente após uma dessas reuniões que esse poeta de Eça reflete, pela primeira vez, sobre sua existência:

\footnotetext{
"Tudo na sua vida era assim incompleto, esboçado; fragmentário; não encontrava nada de sólido onde se ficar, a que se dedicar: amor, relações, glória, tudo lhe escapava dentre as mãos, como a água que uma criança quer apanhar e lhe foge entre os dedos [...]." (QUEIRÓS, 19--, p.119)
}

A reflexão sobre sua mísera biografia não permitiu a Artur a tomada de providências ou a busca por novos caminhos, distantes da hipocrisia social 
e dos parasitas que desprezavam seus (possíveis) talentos, mas amavam seu dinheiro. Os acontecimentos posteriores atestam, mais uma vez, a debilidade moral, o sentimentalismo e o caráter anêmico, cuja fraqueza o impediu de resistir às condições impostas. Assim sendo, o autor de Amores de poeta, em um lapso de autotransformação, integra-se ao Clube Republicano lisboeta como única alternativa para mudar os rumos de sua vida: "Decidia-se então a abandonar todos os hábitos de sociedade, as esperanças vãs em amores fictícios, a literatura puramente lírica; queria trabalhar para o estabelecimento da república [...]" (QUEIRÓS, 19--, p.137).

Tal convicção perdurou por pouquíssimo tempo na mente de Artur - logo ele descobriu que aqueles que deveriam defender a República se reuniam, na verdade, para zombar da vida pessoal dos ministros e da corte. Entre frequentar o Clube (do qual seria expulso devido a um mal entendido) e gozar uma bela pândega, o poeta de $A$ Capital prefere a segunda e, em uma noite boêmia conhece Concha, uma cortesã por quem se apaixona, e rapidamente ele inicia uma relação de aspectos matrimoniais, fazendo de tudo para divertir a amada: "E com camarotes, tipoias, jantarzinhos, o dinheiro ia-se! O conto de réis que Artur trouxera, estava quase 'devorado"” (QUEIRÓS, 19--, p.175).

A preocupação financeira leva-o a buscar nos livreiros o dinheiro proveniente das vendas de seu livro Esmaltes e joias, publicado há pouco. Para a surpresa de Artur, a obra fora totalmente ignorada pelo público e, por isso, não havia lucro nenhum. Mesmo assim, a vida de luxos não é deixada para trás e 0 poeta que até então se alegrava e esquecia-se dos tormentos monetários com a presença de sua concubina é abandonado por ela. Mais tarde, Artur descobre que o próprio Melchior, o amigo tão estimado, também havia sido amante de Concha. O gran finale da ruína do personagem-escritor se dá em um encontro com o velho companheiro Damião - Artur é repudiado (chamado de canalha) por Damião devido ao episódio da expulsão do Clube Republicano:

\footnotetext{
"Sentia um espanto, uma revolta aterrada contra o destino. Por que merecia tudo o que lhe sucedia? Que tinha feito? Era bom, era amante, era inteligente, era honrado - e a cada passo que dava na vida surgia-lhe uma indiferença, um escárnio, uma humilhação, uma traição, uma desfeita. Teve a consciência da sua fraqueza moral, da sua debilidade efeminada! Revoltou-se contra si mesmo... Tinham-lhe chamado canalha, e ficara aparvalhado, numa tremura! Teve ódio à estrutura anêmica do seu corpo, à languidez romanesca da sua alma [...] De que servia na vida?"' (QUEIRÓS, 19--, p.200)
} 
Sem perspectivas e sem dinheiro, Artur resolve voltar para o lugar de onde partira, Oliveira-de-Azeméis. Antes de sua partida, compra com as últimas libras restantes dois pares de luvas pretas e um plastron para usar no luto de tia Sabina (ele já havia sido informado sobre a grave enfermidade que a atingia). Mesmo derrotado, ainda quis levar à província um pouco do status sustentado na capital.

De volta ao interior, tenta ocupar o espírito vazio:

"Então quis fazer versos. Mas, como em Lisboa o barulho da rua, ao princípio, espantara a inspiração - era agora o adormecimento silencioso da vila que parecia afastá-la. Recaiu assim num tédio passivo, morno, cheio de horas vazias; dava longos passeios ao acaso; desmantelava as maxilas em bocejos intermináveis" (QUEIRÓS, 19--, p.222)

O último sopro de esperança de atingir a glória esvaneceu-se com a carta de Melchior avisando o amigo sobre a impossibilidade empresarial de se representar a obra Amores de poeta. Esvanecidas as esperanças literárias, Artur estava fadado a passar o resto de seus dias como um anônimo morador de Oliveira-de-Azeméis, funcionário de uma velha botica.

Ao fazer um balanço de sua própria vida, esse protagonista descobre que não tivera nenhum saldo: nunca possuíra amizades sinceras e nunca pudera contar com sentimentos verdadeiros; a única pessoa que o amara fora a tia Sabina, "uma pobre velha, simples, de coração amante que na vida só tivera lágrimas e que estava agora sob uma lousa, naquele cemitério de que ele via, ao fundo do atalho por onde ia caminhando, os ciprestes agudos [...]" (QUEIRÓS, 19--, p.225).

A atmosfera lúgubre desse espaço no qual Artur faz seu balanço biográfico provavelmente colabora para a simbolização de uma possível morte moral do poeta - não obtivera saldo nenhum em vida até aquele momento. Os mortos, segundo o coveiro, eram os responsáveis por fertilizar o solo, adubando as batatas lá cultivadas. E Artur Corvelo? O que havia feito durante toda a vida? Fora uma criança débil, um estudante medíocre, um sobrinho interesseiro, um poeta parvo... Possuíra uma existência romanesca, traída e iludida diversas vezes. Quiçá morto e enterrado teria ao menos a serventia de alimento do solo. 
Considerações Finais

Analisar um personagem cujo único propósito de vida era alcançar a fama por meio da literatura e que lia obras românticas sem nenhum distanciamento crítico e emotivo, sendo, portanto, um representante de uma ruína inevitável (provocada pela educação falha que o formou e a sociedade hipócrita que o tolerou, inclusive tirando proveito de seu caráter fraco) é reconhecer uma personalidade constituída pela opinião alheia, alimentada por leituras acéfalas e pela superficialidade das relações sociais. Artur só possuía a eloquência, a bazófia: as ideias e até um conhecimento mais profundo sobre a literatura, equivocadamente vista como seu maior talento, faltava-lhe

Pode-se dizer que o poeta de Oliveira-de-Azeméis é vazio, pois está sempre em meio a fatos negativos e, nos únicos momentos nos quais vivencia instantes um pouco menos tediosos, confunde-os com os inúmeros enredos românticos e versos líricos pertencentes às obras lidas desde a mais tenra infância. É por meio dessas idealizações que Artur segue sua vida, como se a biografia que lhe coubera pouco importasse frente aos êxtases românticos e os finais bem-sucedidos das ficções por ele devoradas.

Como já explicitado na introdução, Artur não foi o único personagem eciano a confundir a realidade em que vivia com o mundo das leituras realizadas: Artur e Luísa, de O primo Basílio, apesar de representarem diferentes obras, possuem similaridades, tais como a insatisfação diante da própria sorte e o desejo de fugir ao próprio destino.

Assim, esses e os demais personagens da ficção de Eça de Queirós descritos na primeira parte deste artigo representam um símbolo do fracasso construído, entre outros fatores, pela educação atrofiante promotora de leituras desalinhadas. Mesmo frente a esses caracteres similares, acreditamos que o protagonista de $A$ Capital vai além da representação de um mero títere - com suas ilusões, ideais utópicos e fraqueza de caráter, pode ser visto como um ser metonímico de um Portugal representado pela acidez literária de Eça de Queirós.

É possível dizer que o personagem deste estudo não possuía capacidade de percepção e sua extrema ingenuidade o impedia de reconhecer o parasitismo de suas relações (Rabecaz, Melchior, Concha e demais companheiros de Lisboa apenas desfrutaram de sua parvoíce). A completa ficção na 
qual insistia em levar sua vida real, buscando a sobrevivência (fama, glória e dinheiro) por meio de uma arte que pouco conhecia, já o desvirtuava de um possível caminho glorioso, ou ao menos digno. Devido a esse desconhecimento sobre a literatura, Artur não consegue compreender as críticas recebidas pelos seus escritos: Damião, após ler o drama filosófico, reconheceu no amigo certo talento, o qual estava sendo utilizado de maneira errônea (destinado a obras de um romantismo doentio e infecundo). Mesmo em face às críticas recebidas, os escritos muito surpreenderam Artur por não terem vendido nenhum exemplar e por serem impossíveis de dramatização. Esse personagem, na imensidão idealizada de seus talentos literários, não percebe a própria falta de mérito. Assim, o drama Amores de poeta e o livro Esmaltes e joias podem representar uma relação imediata com seu pseudoescritor: são um fracasso.

Após ver caírem por terra todas as suas ilusões e esperanças de um futuro glorioso no lugar idealizado como detentor de uma civilização elevada, o protagonista queirosiano, sem ter alcançado os sonhos de fama e paixão, conforma-se com seu destino, cuja única opção possível, conforme descrito no item anterior, é a volta para a casa das tias e o emprego em uma pequena botica. Artur enterra-se moralmente em Oliveira-de-Azeméis, local que muito possivelmente seja a representação de um reduto do atraso e da estupidez social de vidas sem progressão.

A capital portuguesa e sua descrição baseada na crítica eciana forneceram a Artur os fatores que contribuíram para sua desgraça: os falsos amigos literatos; os amores fáceis; o high life lusitano e a retórica do Clube Republicano. Tais fatores, somados ao caráter frívolo do protagonista e às demais deformidades de sua personalidade, resultaram na biografia desgraçada desse poeta romântico e medíocre, cujo destino sofre as penas do determinismo de Eça de Queirós.

Esse autor fez do protagonista de $A$ Capital uma vítima do seu olhar cético, crítico e impetuoso sobre as vaidades de sua época, criando assim em sua ficção aquilo que acreditava ser um autêntico representante da decadência intelectual portuguesa do século XIX, cuja escolarização, segundo documentos históricos, era uma das menores do mundo ocidental.

Consideramos cumprido no presente trabalho os objetivos traçados de contribuição para um maior (re)conhecimento de uma obra eciana ainda pouco estudada nos ambientes acadêmicos, de valorização da produção literária queirosiana como um todo, e não apenas por obras de grande conhecimento, 
como $\mathbf{O}$ primo Basílio e $\mathbf{O}$ crime do padre Amaro. Ademais, esta análise linear sobre o protagonista Artur Corvelo e sua trajetória podem auxiliar no aumento do referencial teórico relacionado aos personagens masculinos de Eça, afetados pelos mesmos males deformadores do comportamento das figuras femininas.

Acreditamos ser de extrema importância ressaltar que A Capital e seu protagonista Artur Corvelo levaram-nos a refletir sobre a relação entre leitores e leitura e nos permitiram realizar um paralelo entre três males ainda correntes e utilizados nos mais diversos contextos sociais: a superficialidade das relações, o parasitismo oculto por falsas intenções e a mediocridade de caracteres.

\section{Referências}

CANDIDO, Antonio. Entre campo e cidade. In: Tese e antítese. São Paulo: Companhia Editora Nacional, 1971, p. 29-56

CUNHA, Maria do Rosário. A inscrição do livro e da leitura na ficção de Eça de Queirós. Coimbra: Almedina, 2004.

ECO, Umberto. Seis passeios pelos bosques da fiç̧ão. São Paulo: Companhia das Letras, 1994.

LINS, Álvaro. História literária de Eça de Queiroz. Rio de Janeiro: José Olympio, 1939.

MATOS, A. Campos (Org.). Dicionário de Eça de Queiroz. 2. ed. rev. e ampl. Lisboa: Caminho, 1993.

PERRONE-MOISÉS, Leyla P. Altas literaturas. São Paulo: Brasiliense, 1982.

QUEIRÓS, Eça de. A capital. Introd. de Augusto Pisarra. Rio de Janeiro: Ediouro, 19--.

QUEIRÓS, Eça de. O primo Basílio. Introd. de Augusto Pissarra. Rio de Janeiro: Ediouro, 1997. (Biblioteca Folha, 2)

. A ilustre casa de Ramires. São Paulo: Martin Claret, 1999.

REIS, Carlos. Estudos queirosianos: Ensaios sobre Eça de Queirós e a sua obra. Lisboa, 1999.

VIANA FILHO, Luís. A vida de Eça de Queiroz. 2. ed. Rio de Janeiro: Nova Fronteira, 1984. 
Bruna Maria Severino Bicudo

Referências consultadas

COMPAGNON, Antoine. Os cinco paradoxos da modernidade. Belo Horizonte: Editora UFMG, 1996.

HARMUCH, Rosana Apolonia. Terrorismo na literatura de Eça de Queirós. 2006, 216 f. Tese (Doutorado em Estudos Literários) - Universidade Federal do Paraná, Curitiba.

POE, Edgar Allan. A filosofia da composição. In: Poesia e prosa: obras escolhidas. São Paulo: Ediouro, 2000.

SANTIAGO, Silviano. Eça, autor de Madame Bovary. In: Uma literatura nos trópicos: ensaios sobre dependência cultural. Rio de Janeiro: Rocco, 2000, p. $47-65$

XAVIER, Marcelo. Crítica de costumes era o motivo condutor das romances do escritor português. Disponível em: $<$ http://www.rabisco.com.br/colunas/latim/ latim067.html>. Acesso em: 15 ago. 2008.

Recebido para publicação em: 1 de julho de 2009. Aceito para publicação em: 12 de fevereiro de 2010. 